Revista internacional

de Historia

de la Comunicación

\title{
LA DEFINICIÓN DEL ENEMIGO TRAS EL 11-S. ANÁLISIS COMPARATIVO DE ABC Y EL PAÍS.
}

DOI: http://dx.doi.org/10.12795/RiHC.2014.i02.07

César Rina Simón

Universidad de Navarra

cesrina@gmail.com

Recibido: 6-8-2012

Aceptado: 28-12-2013

Resumen: Los atentados del 11-S han sido el acontecimiento de mayor repercusión mediática de las últimas décadas. El giro de las relaciones internacionales y el creciente belicismo del gobierno de Estados Unidos requirieron de una amplia justificación de la invasión de Afganistán como guerra de civilización y acto de justicia. Los medios de comunicación fabricaron a base de estereotipos la imagen de un "enemigo", Bin Laden y, por extensión, el mundo islámico. El análisis de la línea discursiva de ABC y de EI País nos permitirá reconocer las múltiples aristas del acontecimiento y sus repercusiones.

Palabras clave: Terrorismo islámico, ABC, El País, 11-S, Georg W. Bush.

Abstract: The September 11th terrorist attacks have been the event that has had the greatest resonance in the mass media for the last decades. The international relations shifts and the US Government's increasing militarism required a vast justification to support the invasion of Afganistan, which was defined as a war of civilization and an 
act of justice. The mass media stereotyped the image of the enemy, Bin Laden, and the Islamic world. The editorial analysis made by $\mathrm{ABC}$ and El País will allow us to identify the multiple layers/perspectives of the event.

Keywords: Islamic terrorism, ABC, El País, 9-11, George W. Bush.

\section{El atentado del 11-S y sus primeras interpretaciones.}

"Los infieles yerran, pero a los cristianos les asiste buen derecho."

La Chanson de Rolland.

El atentado del 11-S provocó un giro ideológico y político en el horizonte de certezas simbólicas con las que los Estados Unidos se presentaban ante el mundo tras la caída del Bloque Soviético. Lo que podríamos denominar "civilización occidental" -estados europeos, norteamericanos y otros de cultura anglosajona industrializados $y$ mercantilistas, de tradición cristiana y con modelos políticos liberales-parlamentarios-, desde entonces, vive en una coyuntura de falta de inseguridad que ha provocado una seria disminución de las libertades y los derechos cívicos en favor de un estado de "emergencia" permanente, de multiplicación de las medidas restrictivas y coercitivas y de cuestionamiento de ciertos principios y derechos jurídicos que se remontan a las culturas políticas de las revoluciones liberales burguesas.

La obsesión por la seguridad es legitimada, desde sus orígenes, a partir de la concreción visual y discursiva de un enemigo que quiere acabar con la cultura democrática y capitalista para imponer una teocracia "bárbara" y atrasada. Sin la construcción de éste enemigo, las medidas de seguridad, la inversión militar o la limitación de los derechos cívicos no hubieran sido tan bien acogidas por la opinión pública (Kellner, 2002; Mira González, 2008; Reig, 2004). Es por esto que ante los atentados terroristas contra las Torres Gemelas -símbolo económico de la civilización norteamericana- y contra el Pentágono -jefatura política y militar de los Estados Unidos- y su respuesta armada, fuera necesaria una construcción ideológica por parte de los medios de comunicación y de los poderes político-financieros que, en primer lugar, dirigiesen el objetivo de la sociedad ante un enemigo concretizado y responsable, que debería pagar por los atentados. Había que lanzar al mundo un firme mensaje que afirmaba que las víctimas occidentales serían vengadas (Arundhati, 2002; Auge, 2002; Chomsky, 2001 y 2007; Halperín, 2003; Hobsbawm, 2003, Salazar, 2002, Rosas, 2002). 
Un "nuevo orden" mundial se esbozaba a raíz de los atentados. El "choque de civilizaciones" parecía tomar forma y sentido en los ataques mediáticos y bélicos contra los Estados Unidos. (Huntington, 1996) En este horizonte dicotómico triunfó el recurso a la violencia frente al "enemigo," dirigiéndose a los grupos terroristas islámicos y a los países que les daban acogida. El "nuevo orden" requería nuevas respuestas militares a realidades difíciles de concretar. Así mismo, el terrorismo internacional contaba con un entramado anónimo y una flexibilidad que exigía una transformación de los métodos de hacer la guerra. Sin embargo, los Estados Unidos y sus aliados optaron por la tradicional invasión armada, la cual se acompañó de una profunda fabricación ideológica maniquea sobre el régimen talibán de Kabul.

Los intelectuales "occidentales" interpretaron los acontecimientos en varias vertientes: entre la actitud bélica y vengativa contra un ataque a "nuestro" sistema de valores y la defensa del diálogo, la reflexión y la lucha diplomática frente a la diferenciación civilizacional entre el antiguo mundo colonial y los nuevos colonizadores. (López Roa, 2002) Mario Vargas Llosa se decantó por una interpretación dicotómica entre terrorismo y sociedades libres. Su compromiso sin fisuras era para éstas últimas, sin caer en relativismos "lights", aunque también alertara de los posibles peligros de la radicalización de Israel y del conflicto de Oriente Próximo y la coacción de las libertades individuales en nombre de la seguridad internacional.

«El siglo XXI será el de la confrontación entre el terrorismo de los movimientos fanáticos (nacionalistas o religiosos) y las sociedades libres, así como el siglo XX fue el de la guerra a muerte entre estas últimas y los totalitarismos fascista y comunista. La hecatombe ocurrida en Estados Unidos en la mañana del 11 de septiembre demuestra que, aunque pequeñas y dispersas, aquellas organizaciones extremistas partidarias de la acción directa y la violencia indiscriminada disponen de un extraordinario poder destructivo y pueden, antes de ser derrotadas, causar estragos vertiginosos a la civilización, acaso peores que los de las dos guerras mundiales». (Mario Vargas Llosa, "La lucha final", El País, 16-09-2001).

Umberto Eco, por su parte, propuso una firme labor pedagógica para desarrollar entre las futuras generaciones un diálogo intercultural y una reflexión sobre la superioridad moral occidental heredada del colonialismo decimonónico. En este sentido, se preguntaba:

«¿Creemos que el desarrollo tecnológico, la expansión de los comercios, la rapidez de los transportes es un valor? Muchos así lo piensan, y tienen derecho a juzgar superior nuestra civilización tecnológica. Pero precisamente en el interior del mundo occidental, están aquellos que consideran un valor primario una vida en armonía con un medio ambiente intacto, y por tanto están dispuestos a renunciar a aviones, automóviles, frigoríficos... Así, pues, para definir una cultura 
mejor que otra no basta describirla sino que es precisa la referencia a un sistema de valores al que creemos no poder renunciar. Sólo entonces podemos decir que nuestra cultura, para nosotros, es mejor». (Umberto Eco, "Las guerras santas: pasión y razón, La Repubblica, 5-10-2001).

En contra de la línea bélica norteamericana se posicionaron escritores y pensadores como Edward W. Said, Susan Sontag, Salman Rushdie o John Le Carré. Coincidían que el 11-S se estaba utilizando como pretexto justificador y legitimador de la guerra y negaban las teorías occidentalistas de Samuel Huntington. Para ello, trataron de diferenciar las corrientes del Islam radical y del moderado, presentando el horizonte musulmán con una complejidad socio-cultural que trascendía con creces al reduccionismo beligerante norteamericano. Así lo explicaba Edward Said:

«En realidad, Huntington es un ideólogo, una persona que pretende reducir las civilizaciones y las identidades a lo que no son: compartimientos estancos, herméticamente cerrados, purgados de los millares de corrientes $y$ contracorrientes que dan vida a la historia de la humanidad y que, a lo largo de los siglos, han hecho posible que esa historia no esté hecha solamente de guerras religiosas y conquistas imperiales, sino también de intercambio, de fértil mezcolanza y de intereses compartidos. Esta otra historia, mucho menos visible, se omite para dar campo libre a al afán de destacar una guerra ridículamente comprimida y encorsetada». (Edward W. Said, "El choque de ignorancias", El Mundo, 16-10-2001).

\section{O Susan Sontag,}

"La unidad de la retórica moralizante emitida sin límites por los dirigentes y los medios de comunicación de Estados Unidos en los últimos días no es digna de una democracia madura. Las personalidades más destacadas de Estados Unidos, junto con todos los que tienen pretensiones de serlo, nos han demostrado que su único deber es el de manipular: el deber de impartir confianza y gestionar el dolor. (...) La psicoterapia ha reemplazado a la política, en este caso a la política democrática, que implica desacuerdos y estimula a la sinceridad». (Susan Sontag, "Miremos la realidad de frente", Le Monde, 17-09-2001).

En clave política, Baltasar Garzón o Felipe González apostaron por una solución que pasara por el fomento del protagonismo de la UE y de la justicia internacional frente a las doctrinas más beligerantes, defendidas por pensadores conservadores españoles como César Alonso de los Ríos o Jaime Campmany en las páginas de $A B C$. (Umberto Eco et. al., 2002) José Saramago, en clave ética, enumeraba los problemas que había provocado la religión a lo largo de la historia:

«Pero no han sido ellos, pobres dioses sin culpa, ha sido el factor Dios, ese que es terriblemente igual en todos los seres humanos donde quiera que estén y sea 
cual sea religión que profesen, ese que ha intoxicado el pensamiento y abierto las puertas a las intolerancias más sórdidas, ese que no respeta sino aquello en lo que manda creer, el que después de presumir de haber hecho de la bestia un hombre acabó por hacer del hombre una bestia». (José Saramago, "Matar en nombre de Dios", Clarín, 19-09-2001)

Como podemos comprobar, los intelectuales se posicionaron rápidamente en causas enfrentadas y los conflictos ideológicos y terminológicos se concretaron en los debates reproducidos en torno a la prensa. Además, los medios de comunicación tomaron partido del maniqueísmo de las autoridades, en diferentes niveles, y, mediante imágenes, editoriales y noticias, manipularon los acontecimientos para convertirlos en marcas justificativas de determinadas ideas políticas. Es por ello que nos hemos acercado a la fabricación del enemigo tras el 11-S con el fin de tratar de dilucidar las dicotomías en la prensa, las diferencias ideológicas y la manipulación informativa, siguiendo una metodología que se nutre del análisis a los discursos aplicados a los medios de comunicación y de las técnicas de persuasión informativa y propaganda (Domenach, 1986; Pizarroso Quintero 1990 y 2005; Brown, 1995; Reyzábal, 1999).

Hemos seleccionado para nuestro estudio los editoriales y los artículos de opinión de dos diarios de tendencias ideológicas aparentemente enfrentadas: $A B C$ y El País, con el fin de investigar el grado de construcción y deformación que ejercieron sobre los acontecimientos durante el mes de septiembre de 2001. A sí mismo, hemos comparado el "ruido" y la "redundancia" de las noticias, lo que nos ha permitido un acercamiento a la línea discursiva y estructural de cada periódico (Rodríguez de las Heras, 1983 y 1991; Sánchez González, 2001; Díaz Barrado, 1989 y 1997; Pinilla García, 2007 y 2008). $A B C$, de tradición centenaria, representante de principios conservadores, católicos y monárquicos, manifestó su apoyo al gobierno de José María Aznar en aquella coyuntura. Por su parte, El País, surgido en la "transición española" como referente de la izquierda socialdemócrata, apostó por una respuesta cercana a la planteada por el principal partido de la oposición y manifestó su cuestionamiento a la actitud beligerante del gobierno de George W. Bush. El abanico cronológico de nuestro análisis abarca desde día posterior al atentado -12 de septiembre- hasta el día 30 del mismo mes. Casi veinte días en los que la fabricación del enemigo se fue coloreando de matices y aspectos comparables que evidenciaron la influencia y construcción de la realidad social de los medios de comunicación.

\section{Análisis ideológico de la prensa}


Entendemos por ideología al entramado conceptual que filtra un hecho hasta convertirlo en acontecimiento, es decir, la asimilación de un hecho transmitido y difundido (Koselleck, 1993 y 2001; Cabrera Acosta, 2001; Chartier, 1996). Ante el atentado del 11-S, lo primero que debemos plantearnos es su repercusión en la trama del sistema político. El acontecimiento, por sus múltiples caras y aristas, presentó una difícil comprensión. Partimos de un ataque a los símbolos del poder americano y, por extensión, al mundo globalizado. La carga simbólica del atentado, potenciada por los medios de comunicación, rompió las certezas absolutas de los norteamericanos sobre su papel en el concierto internacional. De esta manera, se produjo un desajuste entre los elementos autoperpetuadores del sistema y la conciencia social, que rápidamente pretendió articular el Presidente Bush en un discurso dicotómico que confería a los estadounidenses el rol de "salvadores de la humanidad" occidental. Este desajuste no sólo se dio en el marco norteamericano. Sus aliados occidentales fueron, indirectamente, víctimas y aliadas de una guerra contra los valores encarnados en el liberalismo, el capitalismo y la democracia laica. Los terroristas conocían el estado de seguridad de la sociedad occidental y el trauma que podrían causar unos ataques en propio terreno americano, lo que los medios de comunicación favorables a la "venganza" rápidamente interpretaron como un nuevo "Perl Harbor."

Para entrar en materia comparativa entre $A B C$ y $E l$ País es necesario establecer tres niveles de análisis que constituyen una totalidad discursiva. Para que el hecho se convierta en acontecimiento tiene que atravesar un proceso de denotación (explicación del significado en el cuerpo de noticias), valoración (representación en los titulares de la escala de importancia del acontecimiento) y argumentación (desarrollo en los artículos de opinión y editoriales del entramado ideológico). En este artículo, hemos considerado oportuno circunscribirnos al plano argumentativo, es decir, a los editoriales -afirmación aparentemente aséptica y general que delimita el posicionamiento oficial del diario- y a los artículos de opinión -que refuerzan, complementan o contradicen los editoriales-. El proceso valorativo y denotativo de construcción del enemigo, manifestado a partir de titulares, patrones, fotografías y vocabulario, requeriría otra monografía.

\subsection{Editoriales}

Las primeras respuestas a los ataques expresaban odio, condolencias y dolor. Tanto para El País como para el $A B C$, estamos ante un ataque a nuestra civilización. No se observa contención en los editoriales. Los medios participaron de la rabia colectiva con opiniones de contenido belicista. Pese a aparente homogeneidad, $A B C$ muestra una tendencia más radical y reitera con más fuerza la idea de que ha sido una declaración 
de guerra. En el editorial del día 12, el periódico dirigido entonces por José Antonio Zarzalejos, interpretaba el atentado como una demostración bélica contra nuestro centro ideológico y cultural, asimilando lo sucedido con "Perl Harbor." Esta comparación, qué duda cabe, le llevaba a defender una respuesta armada de EE.UU., como sucedió en la II Guerra Mundial. Si continuamos con la línea argumental seguida por $A B C$, los terroristas islámicos se asemejarían a los totalitarismos fascistas, en definitiva, a unas fuerzas del mal que tratarían de eliminar nuestros estados libres y democráticos. En este sentido, la respuesta debería ser contundente para acabar con la vulnerabilidad que presentan nuestros sistemas. "Ha llegado el momento de que el mundo nos defendamos para que la democracia no sea la pesadilla de una larga postguerra declarada por el terrorismo» ("Guerra terrorista", $A B C, 12-09-2001$ ).

El País, aunque limitado al día 12, presenta unas líneas argumentativas similares a su homólogo conservador. El atentado supondría un ataque a nuestra civilización, es decir, la aceptación de la existencia de un choque de civilizaciones. El editorial lleva el nombre de "Golpe a nuestra civilización", lo que se puede entender desde una perspectiva connotativa como una cierta aceptación de los presagios de Huntington. Las diferencias surgen cuando El País llama a la calma, ya que «no pueden pagar justos por pecadores». Si la comparación con "Perl Harbor" era recurrente, se utilizó para constatar la fragilidad del "imperio." También extrajo conclusiones contrarias a la política de Bush y su proyecto de "escudo antimisiles" ("Golpe a nuestra civilización", El País, 12-09-2001).

Los días siguientes, los medios trataron de interpretar los atentados con más calma y cautela. El País dio un giro drástico el día 13, centrando su línea editorial en las represalias de Bush antes que en la fabricación de un enemigo, que consideraban más que difuso. El discurso en torno a "Perl Harbor", y la necesaria respuesta de nuestra civilización, se mantuvo presente, pero los matices dirigían la acción principal del problema al presidente norteamericano. Ya que el enemigo era difícil de delimitar, el periódico se oponía a una guerra poco preparada y mostraba su crítica ante los plenos poderes que estaba recibiendo Bush del Congreso norteamericano y las declaraciones bélico-patrióticas del presidente. En último término, la solución pasaba por la mejora de los servicios secretos, últimos responsables de la inoperancia norteamericana ante los atentados.

Sin embargo, $A B C$ mantuvo la línea belicista un día más, hasta que el Rey pronunció un discurso llamando a la calma y a la unidad de los demócratas el día 14. La conmoción y la rabia marcan la línea argumental del periódico. Occidente, en clave de superioridad, abanderó desde la llustración un proceso de libertades marcado por la idea de progreso. Ese mundo había sido atacado y la guerra se hacía inevitable: «nuestra civilización está siendo atacada por el terror, que quiere destruirla e imponernos un régimen medieval» ("Las democracias contra el terror", $A B C, 13-09-2001$ ). La 
dicotomía entre "buenos" demócratas contra "malos" medievales fabricó una imagen tópica del enemigo de la civilización occidental. Y, continuando con la simplificación maniquea, el diario comenzó a relacionar la actividad de los grupos terroristas islamistas y etarras, aspecto en el que El País no se pronunció, produciéndose de esta manera un "ruido" mediático absoluto. Así, el $A B C$ encontró un medio para desprestigiar las acciones terroristas creando un frente global reduccionista.

Tras el discurso moderado del Rey, $A B C$, el día 14, tituló su editorial: "Giro informativo", en una abierta declaración de intenciones. Pasaron a destacar conceptos como "serenidad" y "tranquilidad," alentando a la prudencia al resto de medios. Del mensaje belicista defensivo el periódico mutó hacia el "rearme moral de justicia». Este lenguaje sosegado se mantuvo durante todo el mes en relación a las repercusiones militares de los atentados, aunque mostraran su apoyo a todas las acciones antiterroristas.

En cambio, El País manifestó progresivamente un alejamiento insalvable hacia la respuesta militar de George W. Bush, presentado como un líder exaltado escasamente preparado para un conflicto irracional contra un poder que requería de más inteligencia y menos fuerza. El editorial del día 16 refleja la posición del periódico: Bush ha declarado la guerra -es el agente activo-, calificada como "arrolladora". El artículo destaca la "incertidumbre" y desconfianza hacia Bush. ("Una lucha tenaz", El País, 16-09-2001) Sin duda, el futuro político y la estabilidad del orden mundial, al contrario que $A B C$, superaron en relevancia mediática a los propios atentados terroristas. Más concretamente, el día 17, el editorial denunciaba cómo se estaba utilizando implícitamente la figura de Bin Laden para justificar la cuestionada invasión de Afganistán (Marín Murillo et al., 2004).

Hay que constatar que la línea editorial de $A B C$ incide en menor medida en las repercusiones mundiales de los ataques a EE.UU. El editorial del día 16, "El terror religioso," resulta útil como síntesis de su posicionamiento: se trata de equiparar todos los terrorismos mundiales, tanto nacionalistas como religiosos, sin olvidar de completar la "triada del mal" con el antiguo apoyo del comunismo a los países árabes y las revoluciones sociales como la de Jomeini en Irán.

El día 18 de septiembre, los periódicos dejaron en un segundo plano la información del conflicto para centrarse en las posibles repercusiones bursátiles. La prioridad era salvar el sistema capitalista ante la reapertura de la bolsa de Wall Street. Una vez conseguido, el objetivo se centraría definitivamente en Afganistán, utilizando como "cabeza de turco" a Bin Laden y justificando el ataque contra un poder teocrático cuya única vía de escape pasaba por la entrega del terrorista saudí.

El debate argumentativo giró, en la segunda mitad del mes de septiembre, en torno al régimen talibán. El enemigo estaba creado y el terror imaginario se mantuvo hasta que 
la guerra "inevitable" estalló. La propaganda, en último término, adquiere mayor repercusión si se concentra "en un solo objetivo (regla del único enemigo): hay que localizar un enemigo -una persona, un grupo, un país- y contra él concentrar todos los argumentos. Del mismo modo, la exaltación debe concentrarse en una persona o en un grupo». (Pizarroso Quintero, 1990: 35).

En términos generales, El País se sumó, en apoyo al líder de la oposición y Secretario General del PSOE, José Luis Rodríguez Zapatero, a las decisiones internacionales de la OTAN y la ONU contra el régimen de Kabul y su necesaria fabricación simbólica -el editorial del día 27 estaba escrito en clave militarista, llamando a la unidad internacional ante una larga campaña-. En ese mismo editorial, se defendía el respeto de los derechos humanos ante cualquier tipo de acción y se advertía sobre los peligros que la psicosis y el exceso de seguridad podrían mermar nuestros derechos individuales.

Por su parte, $A B C$, ante el estallido del caso "Gescartera" de corrupción económica en círculos próximos al gobierno de Aznar, trató de centrar la atención en Afganistán y fabricar la imagen de un enemigo más preocupante. Bush, desde el día 19, apuntó directamente al régimen de Kabul. Las páginas de $A B C$ se volcaron en la justificación del ataque norteamericano como acto de legítima defensa. Los editoriales Ilamaron a la unidad de España y a su colaboración internacional ante el estallido inminente de una nueva guerra que, comenzando por los terroristas, podría prolongarse y extenderse. También se señalaba al papel de Pakistán, como en el caso del editorial del día 20 "Pakistán en la encrucijada". El medio conservador participaba de la proclama de Bush "o con nosotros o contra nosotros» y trató de condicionar la neutralidad a países al borde de un conflicto civil. El mensaje de $A B C$ era claro: «Kabul juega con fuego" ( $A B C, 21-09-2001)$. El sujeto de la acción siempre fue el terrorismo, el actor, Afganistán. Bush se limitaba a responder los embistes. Por el contrario, los talibanes protegían a Bin Laden y colaboraban con redes terroristas, lo que justificaba un ataque de EE.UU. Se desarrolló una profunda estigmatización del régimen afgano en relación a sus pautas religiosas o económicas. "Occidente no puede demostrar debilidad intelectual de sus dirigentes ante tal ataque de sentido común" ("Kabul juega con fuego, $A B C, 21-09-2001)$. El carácter católico del diario hace también necesaria una justificación moral de la guerra, que girará en torno a los conceptos de superioridad ideológica y necesidad moral de defenderse de los ataques terroristas y de redención de los civiles "oprimidos" bajo el régimen talibán ("Moral y defensa propia", $A B C, 25$ 09-2001).

Pero el día 26, tras el intento de Bush de acercarse al mundo islámico moderado y la aceptación del gobierno Aznar de esta misión, se produjo un nuevo giro editorial. Para que el mundo civilizado venciera en la guerra contra el terrorismo, debía apoyarse en 
sus aliados musulmanes. La guerra, por lo tanto, ya no era estrictamente de civilizaciones, sino contra el terrorismo global. El giro es sustancial, en tanto que los musulmanes moderados se convirtieron en aliados contra el terror, entrando así en el selecto universo ideológico de los "nuestros". Esta línea editorial continuó hasta los días finales de septiembre.

\subsection{Artículos de opinión}

El apartado anterior, correspondiente a las líneas editoriales, nos ha permitido un acercamiento a la ideología oficial de los medios, que siempre ocultará bajo su moderantismo unas fuertes tensiones ideológicas, muy visibles en los artículos de opinión. A continuación, a través de columnistas habituales e invitados, vamos a reconstruir la ideología que se desprende de los diarios y el ruido interno generado entre sus colaboradores. El amplio grado de disparidad interna dentro de cada periódico evidencia una mayor heterogeneidad ideológica.

En $A B C$ destacamos tres grupos de análisis de lo sucedido. En primer término, encontramos a los columnitas diarios César Alonso de los Ríos, Jaime Campmany y Juan Manuel de Prada -siempre en página impar-, que destacaron por sus interpretaciones belicistas, fatalistas y su justificación de una guerra de civilizaciones. Así mismo, en el medio aparece un heterogéneo sector que participa de los giros editoriales previamente analizados en $A B C$. Y, en último término, sólo encontramos un articulista que en cierta medida cuestione la salida bélica del conflicto: Darío Valcárcel. Los colaboradores de este diario son, en su mayoría, habituales y nacionales.

Por su parte, El País cuenta con una mayor homogeneidad argumentativa y con un elenco de columnistas internacionales de amplio reconocimiento en el estudio de los conflictos Oriente-Occidente. La voz disonante parte del espacio dominical de Mario Vargas Llosa, que sí estimaba oportuna una lucha mundial prodemocrática contra el terrorismo.

La rabia de los atentados marcó, al menos los primeros días, las opiniones en $A B C$. Hay una aceptación de encontrarse en un choque de civilizaciones, en un nuevo "Perl Harbor." Los atentados habían supuesto una declaración de guerra y EE.UU. era sólo un elemento pasivo de la guerra. La dicotomía entre fuerzas del mal y estado democrático fueron constantes y, en último término, legitimaron la guerra. Esta línea fue recurrente para César Alonso de los Ríos y Jaime Campmany. La solución pasaba por apoyar cualquier tipo de acción contra el terrorismo. La justificación de la guerra de Afganistán, a partir del día 19, fue evidente en estos dos periodistas-compañeros de página-. Enfatizaron en la relación de los atentados con la declaración de guerra 
contra los valores democráticos y los peligros de una teocracia antiilustrada. Juan Manuel de Prada, en el mismo sentido, defendía la superioridad de la civilización occidental. "Es una hipocresía hablar de multiculturalismo. No existe terrorismo sin un apoyo popular que suministre coartadas y contingentes humanos» (Juan Manuel de Prada, “Civilización", ABC, 28-09-2001).

Esta terna de articulistas fueron los primeros en articular un discurso comparativo que unía fundamentalismo islámico con el ataque de "Perl Harbor" y el comunismo. Se trataba de un eje del mal que se oponía a la moderación y temple demostrado por Bush, según Campmany (Jaime Campmany, "Los enemigos", ABC, 14-09-2001). Desde las mezquitas, como se apuntaba en "La tercera" del día 20 (Olegario González Cardenal, $A B C, 20-09-2001)$, proliferaban los gritos contra EE.UU. La religión islámica se estaba uniendo, en definitiva, en contra de nuestros valores. Pero a la hora de "demonizar" al enemigo, destacó César Alonso de los Ríos. Consideraba que los islamistas siempre habían predicado la "guerra santa" y que nuestro único destino era vencer el fanatismo, único peligro de la Humanidad ilustrada. Comparaba el caso con la buena fama de la que gozó el comunismo al tiempo que se conocían sus atrocidades (César Alonso de los Ríos, "El Islam realmente existente", ABC, 21-09-2001).

"La Tercera" permitió completar la línea editorial de $A B C$. El día 13, Venancio Pendás titulaba este espacio "Lecciones para ganar una guerra." Partía de la inevitabilidad del conflicto, en tanto que los atentados habían sido una declaración de guerra en toda regla. "Occidente ha sido humillado y tocado en su fondo". La diferenciación cultural de Occidente, partiendo del movimiento llustrado, ha culminado en unos derechos y libertades que debían hacerse universales. "La fuerza y la razón están de nuestra parte" (Venancio Pendás, "Lecciones para ganar una guerra", $A B C, 13-09-2001)$.

Una vez espoleado el acontecimiento bélico, se trató de determinar los rasgos del enemigo. Darío Valcárcel incluía abiertamente a ETA en su análisis ("Wall Trade Center y terrorismo de ETA", $A B C, 13-09-2001)$. Era fundamental la utilización del atentado contra los símbolos norteamericanos para articular un discurso que equiparase el terrorismo islamista con el etarra. De esta línea participó el historiador hispanista Geoffrey Parker ("Reflexiones sobre la I Guerra mundial del siglo XXI, ABC, 16-092001).

El problema alcanzaría los órganos internos de nuestra civilización si las libertades no sabían reaccionar y cortar de raíz los grupos terroristas que surgían de su seno para acabar con el sistema (Ramón Pi, "El Cáncer de las libertades", ABC, 13-09-2001). La permisividad o la "buena fama" en torno a grupos como ETA requería de un replanteamiento de los peligros del terrorismo. Los valores occidentales precisaban ser modificados para que no surgieran grupos que dinamitaran el Estado desde dentro (Ignacio Sánchez Cámara, “Comienza el siglo XXI”, ABC, 15-09-2001). 
La "guerra inevitable" sólo fue cuestionada en las páginas de $A B C$ por Darío Valcárcel, que en línea con la petición de moderantismo por parte del Rey, consideraba que «la ley del talión es hoy impracticable» ("Una respuesta a los suicidas", $A B C, 14-09-2001$ ). Había que recurrir a la diplomacia para lograr una victoria en los despachos que demostrara verdaderamente la superioridad moral de Occidente. La firmeza no garantizaba la victoria en un mundo globalizado. En esta línea, "La tercera" del día 15 recogió la opinión del exsecretario de Estado de la Casa Blanca Henry Kissinger, donde reiteraba el llamamiento a la calma y apostaba por una respuesta meditada, que permitiera alcanzar la victoria sin caer en un peligroso ajuste de cuentas ("La Victoria sobre el terror exige una nueva política", $A B C, 15-09-2001)$.

EE.UU. recibió un tratamiento de agente pasivo, atacado y humillado, que debía liderar la lucha justa contra el terrorismo. Julián Marías esgrimió una ardua defensa moral de la nación que acabó con todos los "males de la contemporaneidad», como fueron el nazismo y el comunismo. De esta manera, se producía un reiterativo árbol genealógico de los males endémicos que se remontaban desde Hitler hasta el actual fundamentalismo islámico.

Una vez articulado el enemigo en torno a los talibanes afganos, sólo quedaba justificar la invasión norteamericana. Se demonizó el régimen de Kabul por su fanatismo religioso y la pobreza y falta de libertades en el que vivían sometidos sus súbditos. EE.UU. no debía esperar a ser atacado nuevamente, como apuntaba Ignacio Sánchez Cámara ("Legítima defensa", $A B C, 22-09-2001)$. Se sucedieron las críticas hacia los organismos internacionales por su pasividad y se espoleó una actuación individual de Bush. Además, Alonso de los Ríos y Jaime Campmany consideraron el día 23 que la izquierda jugaba con una doble moral muy peligrosa en momentos de guerra (César Alonso de los Ríos, "La guerra y la izquierda española", $A B C, 23-09-2001$ y Jaime Campmany, "La desconfianza", $A B C, 23-09-2001)$. Uno de los enemigos, por lo tanto, no se localizaba en Oriente, sino en las democracias occidentales.

¿Cómo se podía justificar la guerra? En los atentados y, como telón de fondo, las atrocidades orientales que Occidente debe detener. Quedaba así articulado el binomio irracionales-violentos frente a demócratas-ilustrados. La justificación religiosa jugó un importante papel a la hora de espolear un conflicto dentro un diario de tradición católica. El Arzobispo de Mérida-Badajoz afirmaba en "La Tercera" el día 24: "La justicia lleva consigo la vindicación de las víctimas inocentes, el castigo de los culpables, la reimplantación del Derecho y el escarmiento para otros criminales». Los términos del castigo giraban en torno al merecimiento y a la inevitabilidad. Dios, de esta manera, estaba de lado de EE. UU. El mensaje pacifista no tenía cabida ante un ataque terrorista tan injusto. En la línea argumental de El País, estas referencias belicistas no aparecen, generando gran ruido informativo. Frente a las posturas 
legitimistas del portavoz de El Vaticano, Navarro Valls, priman en El País las reflexiones moderadas y pacifistas de Juan Pablo II.

En definitiva, en apenas dos semanas, $A B C$ había articulado un discurso ideológico convincente. "Su extraordinaria crueldad (del terrorismo islámico), sin la negación de cualquier principio común de humanidad y sin el rechazo de cualquier idea de transacción con lo que se considera anti-musulmán desde la perspectiva del integrismo más fanático. Esas son las raíces políticas y religiosas del terrorismo islámico» (Luis M. Linde, "Tiempos más difíciles", $A B C$, 28-09-2001).

El País presenta un discurso ideológico bien diferenciado, aunque siempre partiendo de la base de la pertenencia de ambos a un código liberal-demócrata y eurocéntrico. Los articulistas de este diario no apoyaron la intervención armada de Bush, por lo que no encontramos ninguna justificación de la violencia, a excepción de la mencionada postura de Mario Vargas Llosa. Así mismo, defendieron el moderantismo del Islam y la doble moral que aplicaba EE. UU. en su política internacional.

La primera respuesta del periódico fue belicista, motivada sin duda por la consternación inmediata a los atentados. Pese a ello, se hace un llamamiento general a la calma. El director, Juan Luis Cebrían, partiendo de la declaración de guerra, abogaba por reformar la inteligencia y acabar con los apoyos políticos y financieros de los terroristas. Apuntaba la piedra clave del discurso argumental de El País en torno a los orígenes de la violencia: "es un terrorismo de los desheredados, de los que no temen nada porque no tienen nada que perder» ("La política del odio", El País, 12-09-2001). De esta manera, los terroristas actuaban condicionados por la situación injusta que les ha provocado el imperialismo americano. La vía de escape pasaba por cortar de raíz las injusticias y las macrodiferencias. La solidaridad se convirtió en la respuesta más apropiada para el periódico. Los llamamientos a la guerra fueron interpretados por los articulistas como un símbolo más del belicismo norteamericano. Felipe González expuso unas líneas argumentales en defensa de la paz: un rotundo no a la guerra y la negativa al aprovechamiento del rédito político de los atentados ("La globalización del terror", El País, 15-09-2001). Otra posible solución pasaba por apoyar política y moralmente a los regímenes islámicos moderados, para crear así una conciencia de paz y respeto entre Oriente y Occidente. El peso de la irresponsabilidad cayó sobre el presidente Bush, un gran loco que pretendía convertir la política internacional en una inmensa "yihad." (Thomas Friedman, "En la guerra civil del Islam, reforcemos a los buenos", El País, 20-09-2001).

El moderantismo del diario es palpable desde los primeros días. Enrique Gil Calvo, por ejemplo, además de reconocer el choque de culturas que sumirá presumiblemente al siglo XXI en una guerra continua entre civilizaciones, trató de ponerse en la piel del enemigo, haciendo hincapié en que las técnicas terroristas fueron inventadas por los guerrilleros españoles y que -estamos ante otra de las claves según El País del 
conflicto- EE.UU. e Israel habían incumplido tratados internacionales ("Hacia el choque de culturas", El País, 13-09-2001).

El atentado fue explicado como un problema entre centro-periferia, opresoresoprimidos. Suponía una continuidad histórica que no respondía estrictamente a la "incivilidad" de los musulmanes, sino más bien a un compendio de relaciones de poder políticas, económicas y religiosas (Alain Touraine, "La hegemonía de EEUU y la Guerra islamista", El País, 14-09-2001). De ello se extrae que la respuesta americana no podía generar más odio ni más guerra. Los atentados, en su esencia, más que una declaración de guerra, presentaron un espectáculo mediático cuyo objetivo era medrar la seguridad occidental y generar odio a partir de la humillación y el terror.

Si hay un denominador común en la opinión de El País es la crítica reiterativa que efectúan la mayoría de los articulistas al "choque de civilizaciones" de Huntington (Shlomo Avineri, "Ninguna guerra de civilizaciones", El País, 21-09-2001). La argumentación reiterativa asentó la idea de que el acto terrorista no respondió a problemas culturales, sino a injusticias sociales. Además, «el choque de civilizaciones es una idea macabra de los que creen que son el centro del mundo». La solución para Manuel Castells pasaba por superar la exclusión social y la opresión de las identidades ejercida por el poder central imperial norteamericano ("La guerra en red", El País, 1909-2001).

Una de las corrientes visibles fue la de crear una opinión positiva favorable al Islam moderado y separar terrorismo de religión. Menom Yaqub el día 15 publicó un alegato en contra de la demonización del Islam. Sentía temor porque la irracionalidad terrorista había despertado brotes racistas en EE.UU., las cuales estaban provocando el mismo horror que los fundamentalistas. Por lo tanto, la respuesta no podía pasar por una acción unilateral armada. El primer condicionante era ético: "¿ंes justo lanzar bombas contra inocentes en Afganistán?» (Yaqub Menom, "Yo no soy el enemigo", El País, 15-09-2001).

La oposición a la guerra se articuló en la imposibilidad de fijar las líneas de actuación ante un enemigo tan volátil. Las técnicas de guerra debían centrar sus esfuerzos en los servicios de inteligencia, en detrimento del ejército tradicional, que tenía poco sentido en guerras que no se desarrollaban entre fronteras ni naciones determinadas. Además, la invasión podría radicalizar las posturas en los conflictos en Oriente Medio. «Los buques de guerra estimularán el integrismo saudí» (Anthony Simpson, "La represalia militar sigue el juego de Bin Laden", El País, 30-09-2001).

Los artículos de opinión de El País contaban con una información más detallada del conflicto y con un análisis más crítico, en buena medida provocado por la heterogeneidad internacional de sus especialistas. Esta información permitía una mejor conducción ideológica del lector. Encontramos un ejemplo en las explicaciones 
de Antonio Elorza: "La imagen tópica de Osama Bien Laden es la de una versión islámica del malvado en las películas de 007 , solo que en esto caso motivado por los despropósitos de la política de EE.UU.» (“La encrucijada de Alá”, El País, 19-09-2001).

Pilles Koper rompió los esquemas al recurrir a la historia reciente de Afganistán para explicar el atentado. El autor recordó la ayuda prestada de EE.UU. a los rebeldes afganos contra la URSS y cómo las armas norteamericanas permitieron rearmar la "yihad". El artículo era clarividente, al recordar la imagen idílica y de libertad que se fabricó en torno a los yihadistas-talibanes contra el comunismo. Y, además, si EE.UU. apoyó la autonomía de Afganistán frente a la ocupación imperial rusa, debería quizás retirar sus tropas de Arabia, argumentaba Koper. A estos trucos ideológicos, se añadían intereses económicos, como un gran proyecto de gaseoducto norteamericano que cruzaba Afganistán (Pilles Koper, "La trampa de la yihad islámica”, El País, 18-092001). Nuevamente, el ruido con $A B C$ es total.

A partir del día 20, la fijación por parte de la administración Bush del objetivo en Afganistán provocó la reacción ideológica en contra de la inevitabilidad del conflicto. Si $A B C$ establecía una continua comparación de los terroristas con el nazismo y el comunismo, El País recurrió a interpretar la guerra como una reedición de la derrota en Vietnam (Ali Tariqu, "Hace falta una solución política, no militar", El País, 20-092001). La argumentación principal giraba en torno a la doble moral de Occidente, que sólo intervenía en los conflictos que le interesaban económica o estratégicamente. En definitiva, era un poder hipócrita, en tanto que lanzaba bombas atómicas contra civiles y no permitía la posesión de las mismas.

Jeremy Rifkin constataba el peligro de la guerra de Afganistán en clave de pérdida de la inocencia: si nos comportamos como los verdugos en nombre la libertad, perderemos la legitimidad ideológica (“La guerra que hay detrás de la guerra”, El País, 22-09-2001). El problema no era histórico. Tenía como elemento propiciador las diferencias estructurales de la globalización y, resultaba comprensible, que lo que denominamos "tercer mundo" reaccionara ante el proceso homogeneizador. Para acabar con el terrorismo había antes que eliminar las injusticias. En similares términos se expresaba Carlos Fuentes. Hacía hincapié en el final de las certezas absolutas y en la errónea creencia en las definitivas ideas liberales-globalizadoras de EE.UU: «los atentados nos han mostrado los fracasos de nuestro sistema en materia de Justicia y Derechos Humanos» (“Nueva realidad, nueva legalidad", El País, 23-09-2001).

Los artículos de opinión del periódico, ante la inevitabilidad aparente del conflicto, insistían en la complejidad e indefinición del enemigo (Andrés Ortega, "Casi todos, ¿contra quién?", El País, 24-09-2001). La redundancia en la solución pacífica y moderada es completa. Samy Nair resumía esta idea en «actuar sobre las causas profundas del drama», postura abiertamente enfrentada a los planteamientos de $A B C$, que abogaban por una respuesta armada ante lo que entendían como una declaración 
de guerra a nuestro sistema de valores ("Actuar sobre las causas profundas del drama", El País, 26-09-2001). La crítica de El País al gobierno de EE.UU. alcanzó su máxima expresión el día 28 de septiembre, en un artículo de Rossana Rossanda titulado "Notas de una antiamericana." Calificaba a Bush de "chantajista" y acusaba a EE.UU. de ser el único motor de esta nueva guerra. Criticaba así la manipulación informativa y la doble moral occidental a la hora de enfrentarse a la catástrofe: «morirán inocentes por culpa del loco de Bush» (El País, 28-09-2001).

En esta línea, hay que establecer una diferenciación clara entre $A B C$ y El País a la hora de interpretar la censura mediática. $A B C$ trató de entender el control informativo en clave de necesidades de guerra, de tiempo de unidad bajo un mismo discurso que permitiera la victoria de nuestro sistema de valores. En cambio, los articulistas de El País, criticaron la homogeneización informativa y las serias limitaciones que se estaban imponiendo a los periodistas.

La única voz discrepante con esta línea argumentativa fue la de Mario Vargas Llosa en su columna dominical. El domingo 16, en un tono radical de horror hacia los atentados, firmó "La lucha final". La solución del mundo pasaba por quitar -si era necesario por la fuerza- los gobiernos sádicos, sanguinarios y dictatoriales de Afganistán, Irak, Libia y otros. Debía triunfar la democracia, aunque fuera exportada desde Occidente por la fuerza. El escritor peruano fue el único que recurrió en El País al argumento de la inhumana situación de la mujer afgana, sometida a un poder teocrático y machista. EE.UU., como líder del sistema que nos aglutinaba, tenía que liderar una lucha final contra las dictaduras (El País, 16-09-2001). El domingo 30, en un tono más reflexivo, escribió "Las réplicas del 11-S". Acusaba a otros grupos terroristas y a estados dictatoriales de condenar un atentado del que habían participado indirectamente, pero abría una interesante reflexión en contra del exceso de seguridad que podría limitar el bienestar y la libertad (El País, 30-09-2001).

\section{Conclusiones}

A lo largo de las páginas precedentes hemos pretendido analizar el proceso de construcción del "enemigo" -complejo y contradictorio- en la prensa española a raíz del acontecimiento de mayor cobertura mediática del siglo XXI. Este "enemigo" presenta múltiples aristas y una abierta diferenciación entre la opinión del diario $A B C$ y de El País. Sin embargo, los métodos por los cuales la prensa convierte los hechos en acontecimientos presentan profundas similitudes, desde la adjetivación visual a la 
asimilación connotativa del sujeto de la acción en el que recae el constructor dicotómico.

A grandes rasgos, los editoriales y artículos de opinión del diario $A B C$ mostraron un abierto apoyo a las medidas beligerantes del presidente Georges W. Bush, así como aceptaron los planteamientos apologéticos de Samuel Huntington planteados en su obra sobre el choque de civilizaciones. Observamos así mismo una tendencia a recurrir a patrones de valoración eurocéntricos y al recurso retórico a la idea de civilización. En cambio, la información de El País es reconducida ideológicamente hacia el pacifismo, la crítica a la dirección de las relaciones internacionales del gobierno norteamericano y la defensa conceptual del mundo islámico como heterogéneo y principalmente moderado. Sin embargo, los editoriales no dudaron en mostrar su incondicional apoyo a aquellas medidas tomadas por consenso en los organismos supranacionales. En ambos medios, los artículos de opinión complementan, radicalizan y, en el menor de los casos, contradicen, las ideas vertidas por la dirección en los editoriales.

En definitiva, tras el 11-S irrumpió un nuevo enemigo internacional -el terrorismo musulmán individualizado en la figura de Bin Laden- con la capacidad de representar la áurea de barbarie que en las décadas precedentes había recaído en el modelo soviético como medio de legitimación de las doctrinas neoliberales. Así mismo, en determinados medios se construyó una imagen dicotómica en la figura de George W. Bush. Esta construcción del enemigo, sin embargo, distó mucho de seguir un camino lineal orquestado por los medios de información. Más bien, como podemos comprobar en otros procesos análogos de "construcción", ésta se alcanzó a partir del consenso y del disenso entre múltiples discursos, conceptos y significados, complementarios e incluso contradictorios, nunca unívocos. En nuestro estudio, al centrarnos en los veinte días que siguieron al atentado, no hemos podido rastrear el eje diacrónico de la fabricación del enemigo. Nuestro objetivo, en cambio, era más bien limitado: acercarnos a las primeras definiciones de ese enemigo, a los primeros acercamientos conceptuales e ideológicos en las páginas de $A B C$ y $E I$ País, elementos que posteriormente se canalizarían en ideas o conceptos socialmente aceptados.

\section{Referencias bibliográficas}

$A B C$, del 12/09/2001 al 30/09/2001.

ARUNDHATI, Roy (2002): El álgebra de la justicia infinita, Barcelona, Anagrama.

AUGE, Marc (2002): Diario de guerra. El mundo después del 11 de septiembre, Barcelona, Gedisa. 
BROWN, J. A. C. (1995): Técnicas de persuasión. De la propaganda al lavado de cerebro, Madrid, Alianza.

CABRERA ACOSTA, Miguel Ángel (2001): Historia, lenguaje y teoría de la sociedad, Madrid, Cátedra.

CHARTIER, Roger (1996): El mundo como representación. Estudios sobre historia cultural, Madrid, Gedisa.

CHOMSKY, Noam (2001): 9-11, New York, Seven Stories Press.

- (2007): Failed States. The abuse of power and the assault on democracy, London, Penguin Books.

DÍAZ BARRADO, Mario Pedro (1989): Análisis del discurso político, una aplicación metodológica, Mérida, Editora Regional de Extremadura, 1989.

-(1997): Memoria de la palabra: topología del discurso contemporáneo, Cáceres, Universidad de Extremadura, 1997.

DOMENACH, Jean Marie (1986): La propaganda política, Buenos Aires, Editorial Universitaria.

ECO, Umberto et. al. (2002): El mundo después del 11 de Septiembre de 2001, Barcelona, Península.

El País, del 12/09/2001 al 30/09/2001.

FUKUYAMA, Francis (1992): The End of History and the Last Man, New York, Free Press.

HALPERÍN, Jorge (2003): Noam Chomsky. Bush y los años del miedo, Buenos Aires, Fondo de Cultura Económica.

HOBSBAWM, Eric H. (2003): Guerra y paz en el siglo XXI, Barcelona, Crítica.

HUNTINGTON, Samuel P. (1996): The Clash of Civilizations and the Remaking of the World Order, New York, Simon \& Schuster.

KELLNER, Douglas (2002): "El 11 de septiembre. Medios de comunicación y fiebre de guerra", en Signo y Pensamiento, vol. XXI, n. 40, pp. 9-18.

KOSELLECK, Reinhart (1993): Futuro Pasado. Para una semántica de los tiempos históricos, Barcelona, Paidós Ibérica.

-(2001): Los estratos del tiempo: estudios sobre la historia, Barcelona, Paidós Ibérica. 
LOPÉZ ROA, Ángel Luis coord. (2002): La crisis del 11 de septiembre. ¿Qué cambiará?, Madrid, ESIC.

MARÍN MURILLO, Flora, CAMINOS MARCET, José María, ALBERDI EZPELETA, Aintzane y ARMENTIA VIZUETE, José Ignacio (2004): La construcción del mito a través de la prensa: el caso Bin Laden, Sevilla, Comunicación social.

MIRA GONZÁLEZ, Clara María (2008): "La redefinición del enemigo político luego del 11 de septiembre de 2001: un análisis desde la guerra y sus discursos" en Revista Facultad de Derecho y Ciencias Políticas, vol. 28, n. 109, pp. 363-384.

PINILLA GARCÍA, Alfonso (2007): "Información" y "Deformación" en la prensa. El caso del atentado contra Carrero Blanco, Cáceres, Universidad de Extremadura.

-(2008): La transición de papel: El atentado contra Carrero Blanco, la legalización del PCE y el 23-F a través de la prensa, Madrid, Biblioteca Nueva, 2008.

PIZARROSO QUINTERO, Alejandro (1990): Historia de la propaganda. Notas para un estudio de la propaganda política y de "guerra", Madrid, EUDEMA.

- (2005): Nuevas guerras, vieja propaganda. De Vietnam a Irak, Madrid, Cátedra.

REIG, Ramón (2004): Dioses y diablos mediáticos: cómo manipula el poder a través de los medios de comunicación, Sevilla, Urano.

REYZÁBAL, María Victoria (1999): Propaganda y manipulación, Madrid, Acento.

RODRÍGUEZ DE LAS HERAS, Antonio (1983): Crisogramas: el lenguaje de la crisis en los sistemas políticos, Cáceres, Universidad de Extremadura.

-(1991): Navegar por la información, Madrid, Fundesco.

ROSAS, María Cristina coord. (2002): Cuando el destino nos alcance... Terrorismo, democracia y seguridad, México, Quimera.

SALAZAR, Ana María (2002): Seguridad nacional hoy. El reto de las democracias, México, Aguilar Nuevo Siglo.

SÁNCHEZ GONZÁLEZ, Juan (2001): El ideario regionalista en Extremadura: topología discursiva de José López Prudencio, Cáceres, Universidad de Extremadura. 